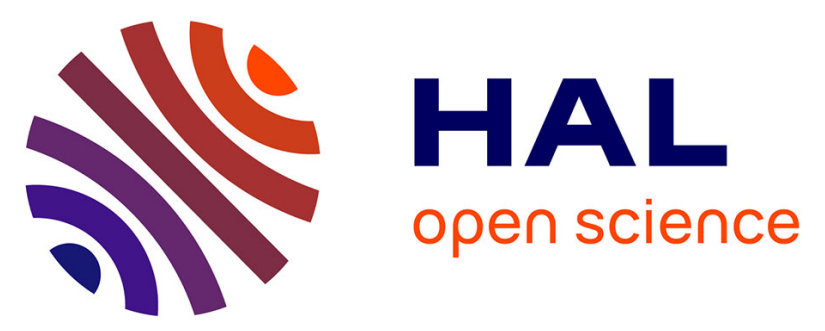

\title{
Aromatic Formation Promoted by Ion-Driven Radical Pathways in EUV Photochemical Experiments Simulating Titan's Atmospheric Chemistry
}

Jérémy Bourgalais, Nathalie Carrasco, Ludovic Vettier, Antoine Comby, Dominique Descamps, Stephane Petit, Valérie Blanchet, Jerôme Gaudin, Yann Mairesse, Bernard Marty

\section{To cite this version:}

Jérémy Bourgalais, Nathalie Carrasco, Ludovic Vettier, Antoine Comby, Dominique Descamps, et al.. Aromatic Formation Promoted by Ion-Driven Radical Pathways in EUV Photochemical Experiments Simulating Titan's Atmospheric Chemistry. Journal of Physical Chemistry A, 2021, 125 (15), pp.31593168. 10.1021/acs.jpca.1c00324 . insu-03201041

\section{HAL Id: insu-03201041 https://hal-insu.archives-ouvertes.fr/insu-03201041}

Submitted on 18 May 2021

HAL is a multi-disciplinary open access archive for the deposit and dissemination of scientific research documents, whether they are published or not. The documents may come from teaching and research institutions in France or abroad, or from public or private research centers.
L'archive ouverte pluridisciplinaire HAL, est destinée au dépôt et à la diffusion de documents scientifiques de niveau recherche, publiés ou non, émanant des établissements d'enseignement et de recherche français ou étrangers, des laboratoires publics ou privés. 


\section{Aromatic Formation Promoted by Ion-Driven}

\section{Radical Pathways in EUV Photochemical \\ Experiments Simulating Titan's Atmospheric \\ Chemistry}

Jérémy Bourgalais, ${ }^{*, \dagger},+\|$ Nathalie Carrasco,$^{\dagger}$ Ludovic Vettier, $^{\dagger}$ Antoine Comby, ${ }^{\top}$ Dominique Descamps, "Stéphane Petit, "Valérie Blanchet, Jérôme Gaudin, " Yann Mairesse, and Bernard Marty ${ }^{\S}$

$\dagger$ †ATMOS-IPSL, Université Versailles St-Quentin, CNRS/INSU, Sorbonne Université, UPMC Univ. Paris 06, 11 boulevard d'Alembert, 78280 Guyancourt, France $\ddagger$ Centre de Recherches Pétrographiques et Géochimiques, UMR 7358 CNRS-Université de Lorraine, 15 rue Notre Dame des Pauvres, BP 20, F-54501 Vandoeuvre-lès-Nancy, France \CELIA, Université de Bordeaux-CNRS - CEA, UMR5107, 351 Cours de la Libération

$$
\text { F33405 Talence, France }
$$

$\S$ Centre de Recherches Pétrographiques et Géochimiques, UMR 7358 CNRS - Université de Lorraine, 15 rue Notre Dame des Pauvres, BP 20, F-54501 Vandoeuvre-lès-Nancy, France ||Current Address: Laboratoire Réactions et Génie des Procédés, CNRS, Université de Lorraine, BP 20451, 1 rue Grandville, 54000 Nancy, France

E-mail: jeremy.bourgalais@univ-lorraine.fr

Phone: +33.(0)3.72.74.38.17

Abstract 
In the atmosphere of Titan, Saturn's main satellite, molecular growth is initiated by $85.6 \mathrm{~nm}$-Extreme UltraViolet (EUV) photons triggering a chemistry with charged and free-radical species. However, the respective contribution of these species to the complexification of matter is far from being known. This work presents a chemical analysis in order to contribute to a better understanding of aromatic formation pathways. A gas mixture $\mathrm{N}_{2} / \mathrm{CH}_{4}(90 / 10 \%)$ within the closed SURFACAT reactor was irradiated at relatively low pressure (0.1 mbar) and room temperature for six hours by EUV photons $(\sim 85.6 \mathrm{~nm})$. The neutral molecules formed at the end of the irradiation were condensed in a cryogenic trap and analyzed by electron ionization mass spectrometry. An analysis of the dominant chemical pathways highlights the identification of benzene and toluene and underlies the importance of small ion and radical reactions. On the basis of the experimental results, a speculative mechanism based on sequential $\mathrm{H}$ elimination $/ \mathrm{CH}_{3}$-addition reactions is proposed for the growth of aromatics in Titan's atmosphere. Elementary reactions to be studied are given to instill future updates of photochemical models of Titan's atmosphere.

\section{INTRODUCTION}

Within the Solar system, Titan is a model for prebiotic chemistry that makes it a proxy for potential exoplanets that would possess atmospheres with complex organic chemistry. It is now accepted that photochemical processes in the atmosphere of Titan, the largest of Saturn's 62 moons, directly influence the chemical composition of the liquid lakes and the surface hydrological activity. Thus, a detailed understanding of the chemistry of Titan's atmosphere is the way forward to a whole Titan modeling of the composition of the bulk atmosphere and the flux of condensable material to the surface ${ }^{1}$. In the thermosphere between 700 and $1100 \mathrm{~km}$ in altitude, $\mathrm{N}_{2}$ and $\mathrm{CH}_{4}$ are ionized and dissociated mainly by energetic Extreme UltraViolet (EUV) photons from solar radiation, leading to the formation 
of reactive species like ions and radicals among a diverse range of hydrocarbon species. In the lower layers of the atmosphere, below $500 \mathrm{~km}$, hydrocarbons such as benzene and other aromatics by interaction with lower energy UV photons (> $155 \mathrm{~nm}$ ) are key compounds in the formation of larger and more complex molecules like Polycyclic Aromatic Hydrocarbons (PAHs). The existence of PAHs or heterocyclic aromatic compounds has recently been suggested by Cassini/INMS (Ion and Neutral Mass Spectrometer) ${ }^{2,3}$ and Cassini/VIMS (Visual Infrared Mass Spectrometer) measurements ${ }^{4}$.

These species are composed of multiple aromatic rings with delocalized $\pi$-electrons that make them stable structures. These molecules are the intermediate step that separates small organic molecules such as acetylene, and larger carbonaceous materials. They contribute to the production of aerosols which form the opaque photochemical haze layers that obscure the surface of $\operatorname{Titan}^{5,6}$. Thus the identification of the pathways of formation of these species is essential for understanding the chemistry of Titan's atmosphere, but is yet to be fully understood even for the simplest PAH precursor, namely benzene $\left(\mathrm{C}_{6} \mathrm{H}_{6}\right)$ and toluene $\left(\mathrm{C}_{7} \mathrm{H}_{8}\right)$.

So far, benzene is the most abundant and most complex large neutral molecules that has been reliably identified to date in Titan's atmosphere, both by modelling data from Cassini/INMS ${ }^{3,7}$ and observations by optical spectroscopy from ISO (Infrared Space Observatory) and Cassini/CIRS (Composite InfraRed Spectrometer) ${ }^{8,9}$. Nonetheless the mass spectra present a signal up to mass 91. Photochemical models have highlighted neutral and ions dissociative recombination reactions that lead to the formation of benzene in the upper atmospheric layers where its significant molar fraction is of the order of $\mathrm{ppm}^{10-14}$. However, even the most recent model predictions systematically underestimate the abundance of benzene with uncertainties that vary the mole fraction by several orders of magnitude while the identification of formation processes for larger hydrocarbons are even more uncertain ${ }^{15,16}$. This highlights the need for new inputs from laboratory studies to reach an understanding of the chemistry occurring in Titan and more specifically the formation pathways of aromatic molecules. 
The incident solar radiation is mostly dominated by wavelengths above $100 \mathrm{~nm}^{17}$. However, it is the EUV photons that are absorbed in thermosphere and initiate chemistry, while photons at lower energy penetrate deep into Titan's atmosphere ${ }^{15}$. Photons whose wavelength is shorter than $80 \mathrm{~nm}$ are absorbed above $1,000 \mathrm{~km}$. On the other hand, photons with wavelengths between 80 and $100 \mathrm{~nm}$ penetrate to altitudes between 800 and 1,000 km. This altitude coincides with the maximum of the molar fraction of benzene predicted in the atmosphere of $\operatorname{Titan}^{16}$.

The present work reports on this chemical regime in which nitrogen is dissociated and methane is mostly ionized. In order to achieve this, the approach used in this work consists in reproducing the chemistry that takes place in Titan's atmosphere in the laboratory, by irradiating a mixture of gases representative of this environment with an EUV photon source. This approach remains uncommon since synchrotron radiation and high harmonic generation (HHG) of femtosecond lasers are the only EUV photon sources providing sufficient ionization rates to reproduce Titan's chemistry in reasonable laboratory time scale. However, a compromise has to be considered on the exposure time so that the laboratory experiments respect the low dose of energy deposited per molecule in Titan's atmosphere. This is to avoid the formation of species that would not be involved in the initial aerosol formation processes. These experiments can then last several tens of hours to form a quantity of analyzable matter, leading to extensive exposition to possible contamination problems. Thus, long stable low pressure experiments for the irradiation of gas mixtures with a suitable and tunable EUV photon flux for producing photochemical aerosols are challenging to set up.

To achieve that, the recently developed atmospheric simulation chamber SURFACAT (french acronym for surfatron chambre à tholins) has been used ${ }^{18}$. This new experimental platform has been coupled to the EUV light source of the BlastBeat laser system at the CELIA laboratory in Bordeaux, France ${ }^{19}$. 
The feasibility of irradiating for several hours a low pressure gas sample in the SURFACAT reactor to form photoproducts using a stable EUV photon flux was recently presented in Bourgalais et al. ${ }^{18}$. This paper presents a first series of results relating to the study of Titan's chemistry through the use of an experimental device with a low level of contamination. The paper is organized as follows. A description of the experimental setup is given in section 2. Then, the mass spectrum obtained after 6 hours of irradiation is presented and compared to the Cassini/INMS data and the photochemical models in section 3. In section 4, a discussion is made on the transposition of these experimental results to the atmosphere of Titan. Finally, in the last section, radical and ionic pathways to be added in photochemical models are proposed in order to advance our knowledge on the growth of molecular complexity in Titan's atmosphere.

\section{EXPERIMENTAL METHOD}

In this study a nonlinear optics approach has been used to generate an intense and stable light in the EUV range to reproduce the dominant chemical processes in the upper atmosphere of $\operatorname{Titan}^{20}$. The EUV light was produced by the HHG of the BlastBeat laser system at CELIA, based on Yb-Doped Fiber Amplifier (YDFA) technology ${ }^{21}$. In this work a monochromatic source at $14.5 \mathrm{eV}(\sim 85.6 \mathrm{~nm})$ was obtained by selecting the third harmonic generated in gas jet of argon of the fourth frequency of the YDFA laser. The repetition rate of this laser source was set at $166 \mathrm{kHz}$ (its lower limit). The fourth harmonic beam generated by two BBO crystals in cascade reached $6 \mu \mathrm{J} /$ pulse and were magnified by a $\times 5$ mirror telescope and focused by a $300 \mathrm{~mm}$ focal length. The transmittive optics were in high quality Ramangraded $\mathrm{CaF}_{2}$. After a reflexion on a $\mathrm{SiO}_{2}$ mirror at $60^{\circ}$ incidence angle, the EUV light was injected into the SURFACAT photoreactor through a $150 \mathrm{~nm}$ thick indium foil, which has a measured transmission of $15 \%$ around $14.5 \mathrm{eV}$, and completely blocks the fundamental radiation at $257 \mathrm{~nm}$ and any other of its harmonics. The source-filter distance was calculated, 
by estimating the divergence, so that the beam size is equivalent to the useful diameter of the filter.

The experimental setup has already been described in the literature and thus, only the specificities related to this study are described in this section ${ }^{18}$. Each part of the reactor was cleaned with ethanol before assembly and the reactor was then pumped to a secondary vacuum and heated for 48 hours at a temperature sufficient to minimize the contribution of water vapor and organic pollutants whose presence is checked before each irradiation. The 85.6 nm-EUV light irradiated for 6 hours, a gas mixture composed of nitrogen and methane $\left(90 / 10 \%\right.$ ) injected into the reactor (volume $\sim 1 \mathrm{dm}^{3}$ ) at a total pressure of 0.1 mbar and room temperature. It should be noted that the ratio of methane to nitrogen in this gas mixture is about 2 to 3 times higher than in Titan's atmosphere at altitudes of 800 - 1,000 km. This choice was made in order to favor the formation of hydrocarbons in the reactor $^{22}$. This closed-cell irradiation technique allows us to reproduce the molecular growth taking place in Titan's highly diluted atmosphere in a reasonable time on Earth. A Titan day lasts almost 16 terrestrial days and the average solar flux is $5 \times 10^{6}$ photons s $\mathrm{cm}^{-2}$. Considering that in this work, the photon flux reaching the gas mixture was measured to be $4 \times 10^{11}$ photons $\mathrm{s}^{-1} \mathrm{~cm}^{-2}$, this device reproduced one day of irradiation on Titan into 17 seconds. The EUV flux was measured after the indium filter with a calibrated photodiode before the insertion of the gases as well as after the mass spectra measurements.

The product analysis was ensured by a quadrupole mass spectrometer using $70 \mathrm{eV}$ electron ionization to detect the neutral species and as follows: (1) Before irradiation, a $1^{\text {st }}$ mass spectrum of all species present in the reactor is recorded. (2) At the end of the irradiation, a $2^{\text {nd }}$ mass spectrum is recorded so that the consumption of methane can be measured. (3) The photoproducts are condensed in a liquid nitrogen trap and a VAT valve allowing to separate the reactor into two closed parts. (4) The photoproducts are then released into the part with the smaller volume (volume ratio of 3.5). (5) The photoproducts are then recondensed in the cryogenic trap and the reactor is pumped to a secondary vacuum 
to minimize the presence of the dominant $\mathrm{N}_{2}$ and $\mathrm{CH}_{4}$. (6) The products are finally released into the reactor and a $3^{\text {rd }}$ mass spectrum is acquired.

A background correction has been made on the $3^{\text {rd }}$ mass spectrum by subtracting the $1^{\text {st }}$ mass spectrum and the result is shown in Figure 2 hereafter. The absence of signal at $\mathrm{m} / \mathrm{z} 18$ in the mass spectrum of Figure 2 is due to the fact that the intensity of the peak at $\mathrm{m} / \mathrm{z} 18$ is approximately the same before and after irradiation. This mass corresponds to the residual water signal which is irremediably the main pollutant in the system despite efforts made upstream of the experiments to desorb the experimental device. However, this similarity of the water signal before and after irradiation reveals that the role of water in the chemistry of the reactor is minimal.

It should be mentioned that the following analysis is based on the mass spectrum interpretation resulting from ionization of molecules by electrons at $70 \mathrm{eV}$. This ionization technique leads to a fragmentation of the newly formed molecules that must be taken into account. The signal of each mass may result from a contribution of several fragments coming from parent molecules. As mentioned in Bourgalais et al. ${ }^{18}$, the National Institute of Standards and Technology (NIST) (http://webbook.nist.gov/) fragmentation database has been used as a reference for the fragmentation patterns involved here.

\section{RESULTS}

The total reactivity efficiency of the reactor irradiated at $85.6 \mathrm{~nm}$ wavelength can be estimated by measuring the methane consumption. Figure 1 shows the relative methane consumption after only one hour of irradiation of a $\mathrm{N}_{2} / \mathrm{CH}_{4}$ mixture $(90 / 10 \%)$ at a total pressure of 0.1 mbar in the photoreactor. The calculation was performed using each of the four methane fragments to ensure the reliability of the measurement. The respective signal of each fragment before $\left(\left(\mathrm{CH}_{4}\right)_{0}\right)$ and after irradiation $\left(\left(\mathrm{CH}_{4}\right)_{t}\right)$ was subtracted and divided 
by the value before irradiation which serves as a reference. A consumption of about $6 \%$ of the $10 \%$ of methane initially composing the gas mixture was measured. This corresponds to about $10^{-3}$ of the total fraction of the gas mixture. In order to maximize product formation, the irradiation time was subsequently increased to 6 hours.

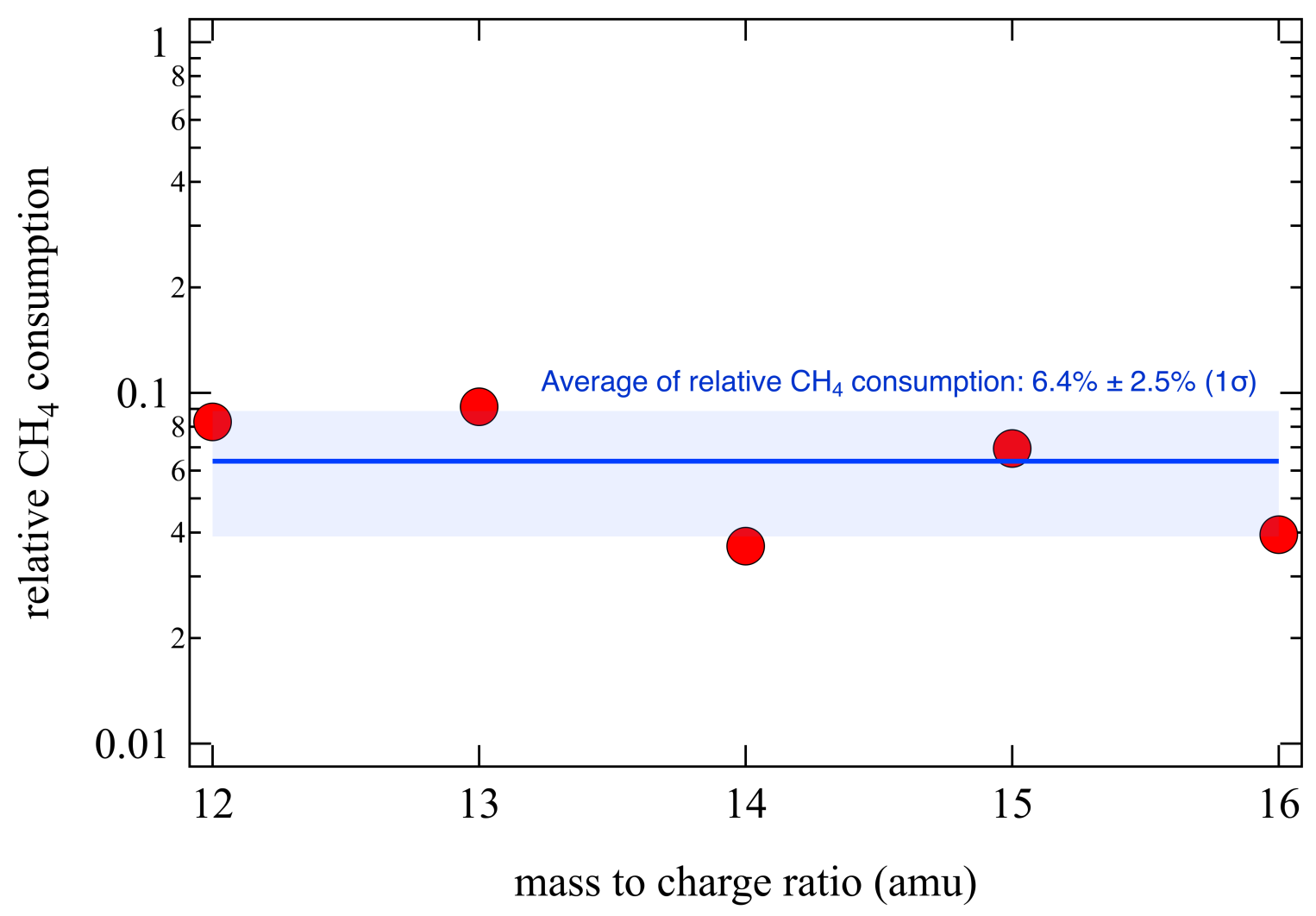

Figure 1: Relative methane consumption $\left(\left(\left(\mathrm{CH}_{4}\right)_{0^{-}}\left(\mathrm{CH}_{4}\right)_{t}\right) /\left(\mathrm{CH}_{4}\right)_{0}\right)$ during one hour of EUV irradiation of a $\mathrm{N}_{2} / \mathrm{CH}_{4}$ mixture $(90 / 10 \%)$ at 0.1 mbar. Each mass related to methane was used to obtained a value of the relative methane consumption (red dots). The blue line is the average of the red dots and the blue area displays the standard deviation.

Figure 2 shows a background corrected mass spectrum obtained after 6 hours of irradiation at $85.6 \mathrm{~nm}$ (see experimental section for more details). This mass spectrum is normalized by mass 28 to be compared to the average neutral mass spectrum from 1 to 99 atomic mass unit measured during T19 flyby by INMS between 950 and 1,000 km in Titan's atmosphere. ${ }^{3}$ The striking result is that despite the wavelength selectivity used, the experimental mass spectrum resembles that of INMS with similar mass coverage and close relative intensities. 
Differences are observed for the mass ranges 50-60 and 80-90. Masses above 100 cannot be directly compared with INMS, since this probe do not go beyond 90. One would also noted peaks located at $\mathrm{m} / \mathrm{z} 32$ and 44 coming from $\mathrm{O}_{2}$ and $\mathrm{CO}_{2}$ due to inherent micro-leaks during the long time of irradiation. The amount of methane is higher than in Titan's atmosphere as expected from our gas mixture and the photoproducts with the trap have been condensed and therefore slightly concentrated. Thus the relative abundances between $\mathrm{N}_{2}$ and the products must be taken with peculiar care. In spite of this, the orders of magnitude are similar and the identification of the products as well as their formation paths remain legitimate. The laboratory-based data presents a broader spectrum with signals to masses not present in INMS and gives the opportunity to explore the common pathways leading to the formation of aromatic molecules in the reactor and the atmosphere of Titan.

\section{The Formation of Benzene in the Photochemical Reactor}

Among the masses of common interest with INMS, that of $\mathrm{m} / \mathrm{z} 78$ is particularly interesting since it correlates with the mass of benzene. The photochemical reactor environment is dominated by energetic photons that initiate the photoionization of methane. At the wavelength used in this work $(85.6 \mathrm{~nm})$ the major output pathways of methane photolysis are $\mathrm{CH}_{3}^{+} / \mathrm{CH}_{4}^{+}$ions along with $\mathrm{CH}_{3}$ and $\mathrm{CH}$ radicals, while nitrogen is dissociated into atoms in their excited state $\mathrm{N}\left({ }^{2} \mathrm{D}\right)$ and fundamental state $\mathrm{N}\left({ }^{4} \mathrm{~S}\right){ }^{23,24}$ :

$$
\begin{aligned}
\mathrm{CH}_{4}+\mathrm{h} \nu(85.6 \mathrm{~nm}) & \longrightarrow \mathrm{CH}_{4}^{+} \\
& \longrightarrow \mathrm{CH}_{3}+\mathrm{H} \\
& \longrightarrow \mathrm{CH}_{3}^{+}+\mathrm{H} \\
& \longrightarrow \mathrm{CH}+\mathrm{H}_{2}+\mathrm{H}
\end{aligned}
$$

These species react mainly with $\mathrm{CH}_{4}$ which is in excess in the reactor and form the ions $\mathrm{C}_{2} \mathrm{H}_{5}^{+}, \mathrm{CH}_{5}^{+}$and the neutral $\mathrm{C}_{2} \mathrm{H}_{4}$ respectively: 


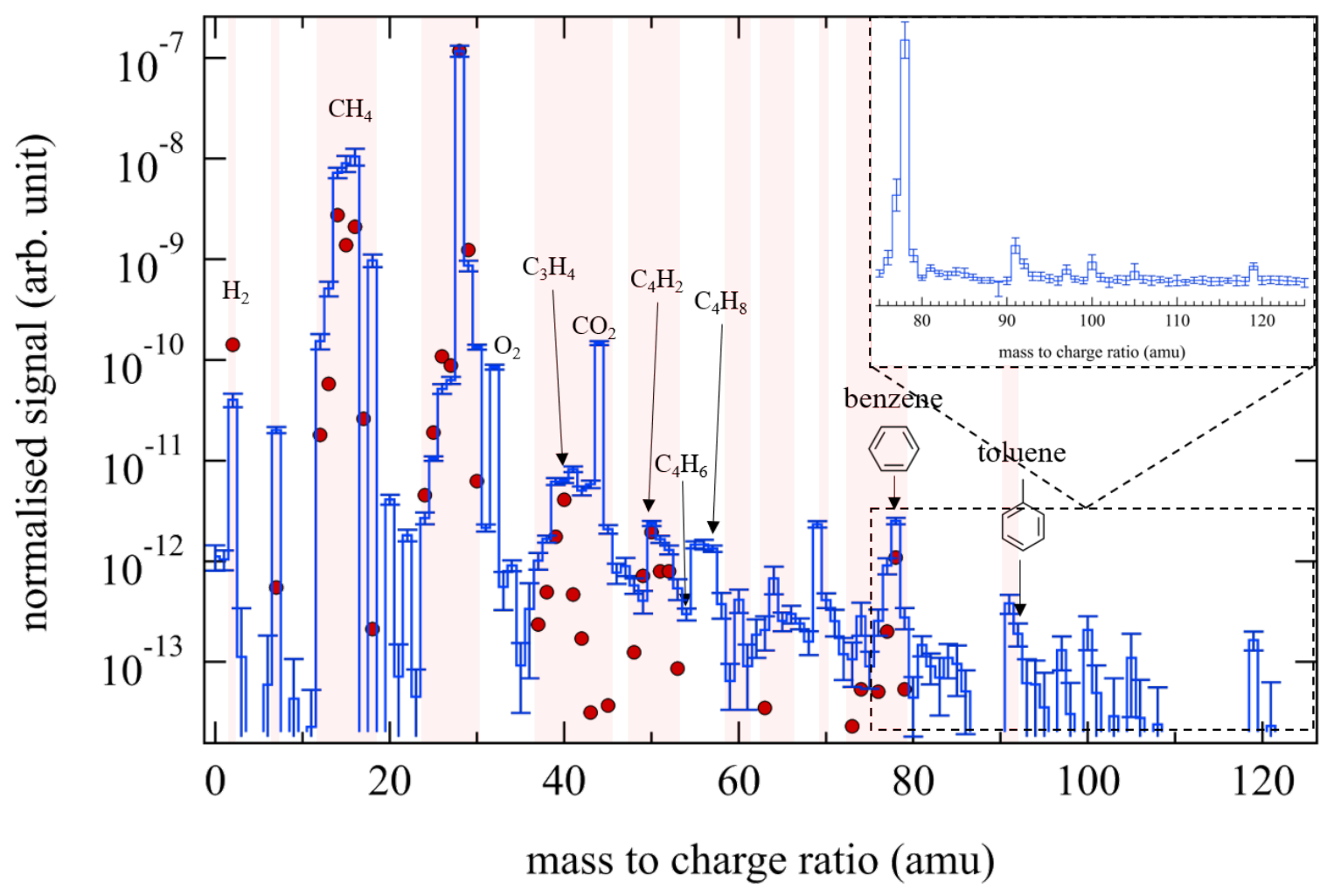

Figure 2: Mass spectrum obtained after 6 hours of irradiation at $85.6 \mathrm{~nm}$ (blue bars) compared to the average neutral mass spectrum from Waite et al. ${ }^{3}$ measured during T19 flyby by INMS between 950 and 1,000 km in Titan's atmosphere. The red areas correspond to the masses at which INMS has detected a signal. The red dots correspond to the relative intensities of the molecules derived from the analysis of the INMS data. The absence of a red dot in a red zone means that no molecule was assigned to this mass during the analysis of the INMS data or that the relative intensity is lower than the scale of the mass spectrum. Data are normalized by $\mathrm{m} / \mathrm{z} 28$ and two standard deviations are displayed for experimental data uncertainties. The noise level of the blue signal is around $10^{-14}$. The dotted box is a zoom of the mass range from 75 to $125 \mathrm{amu}$ in linear scale. 


$$
\begin{gathered}
\mathrm{CH}_{3}^{+}+\mathrm{CH}_{4} \longrightarrow \mathrm{C}_{2} \mathrm{H}_{5}^{+}+\mathrm{H}_{2} \\
\mathrm{CH}_{4}^{+}+\mathrm{CH}_{4} \longrightarrow \mathrm{CH}_{5}^{+}+\mathrm{CH}_{3} \\
\mathrm{CH}+\mathrm{CH}_{4} \longrightarrow \mathrm{C}_{2} \mathrm{H}_{4}+\mathrm{H}
\end{gathered}
$$

The $\mathrm{CH}_{5}^{+}$ion predominantly recombines with electrons to form methane again:

$$
\mathrm{CH}_{5}^{+}+\mathrm{e}^{-} \longrightarrow \mathrm{CH}_{4}+\mathrm{H}
$$

After methane, $\mathrm{CH}_{3}$ is the most abundant neutral coming from charge transfer from $\mathrm{CH}_{3}^{+}$ and $\mathrm{CH}_{4}^{+}$with $\mathrm{N}_{2}$. On the other hand, one the major exit channel for the recombination of $\mathrm{C}_{2} \mathrm{H}_{5}^{+}$ions, along with acetylene, is the ethylenyl radical $\left(\mathrm{C}_{2} \mathrm{H}_{3}\right)^{25,26}$. $\mathrm{C}_{2} \mathrm{H}_{3}$ plays an important role in Titan's atmosphere since its reaction with radical $\mathrm{C}_{4} \mathrm{H}_{3}$ is one of the major neutral reactions for the formation of benzene at low altitude ${ }^{15,16}$, through the formation of the phenyl readical $\left(\mathrm{C}_{6} \mathrm{H}_{5}\right)$ to which a H-atom is added to form benzene ${ }^{27}$ :

$$
\begin{aligned}
& \mathrm{C}_{2} \mathrm{H}_{5}^{+}+\mathrm{e}^{-} \longrightarrow \mathrm{C}_{2} \mathrm{H}_{3}+\mathrm{H}_{2} \\
& \mathrm{C}_{2} \mathrm{H}_{3}+\mathrm{C}_{4} \mathrm{H}_{3} \longrightarrow \mathrm{C}_{6} \mathrm{H}_{5}+\mathrm{H} \\
& \mathrm{C}_{6} \mathrm{H}_{5}+\mathrm{H} \longrightarrow \mathrm{C}_{6} \mathrm{H}_{6}
\end{aligned}
$$

It should be noted that theoretical investigations on $\mathrm{C}_{2} \mathrm{H}_{3}+\mathrm{C}_{4} \mathrm{H}_{3}$ also showed that this reaction is barrierless and that there are low energy pathways that can lead directly to benzene products ${ }^{28}$.

$\mathrm{C}_{2} \mathrm{H}_{4}$ leads mainly after a sequence of electronic recombination and photolysis to the formation of small ions: $\mathrm{C}_{2} \mathrm{H}_{2}^{+}, \mathrm{C}_{2} \mathrm{H}_{3}^{+29}$. These ions then react mainly with methane due to its abundance and give the ion $\mathrm{C}_{3} \mathrm{H}_{5}^{+}$which is at the origin by electronic recombination of many $\mathrm{C}_{3}$ radicals including propargyl $\left(\mathrm{C}_{3} \mathrm{H}_{3}\right) \cdot \mathrm{C}_{3} \mathrm{H}_{3}$ recombination constitutes the other important neutral route for the formation of benzene in Titan's atmosphere. It should be 
noted that despite benzene as the main products, $\mathrm{C}_{6} \mathrm{H}_{6}$ isomers (fulvene and 2-ethynyl-1,3-butadiene) are also formed through minor channels ${ }^{30}$ :

$$
\begin{aligned}
\mathrm{C}_{2} \mathrm{H}_{2}^{+} / \mathrm{C}_{2} \mathrm{H}_{3}^{+}+\mathrm{CH}_{4} \longrightarrow \mathrm{C}_{3} \mathrm{H}_{5}^{+}+\mathrm{H}_{2} \\
\mathrm{C}_{3} \mathrm{H}_{5}^{+}+\mathrm{e}^{+} \longrightarrow \mathrm{C}_{3} \mathrm{H}_{3}+\mathrm{H}_{2} \\
\mathrm{C}_{3} \mathrm{H}_{3}+\mathrm{C}_{3} \mathrm{H}_{3} \longrightarrow \mathrm{C}_{6} \mathrm{H}_{6}
\end{aligned}
$$

$\mathrm{C}_{3} \mathrm{H}_{5}^{+}$could also be an additional source of phenyl radical $\mathrm{C}_{6} \mathrm{H}_{5}$. Referring to the statistical approach presented by Plessis et al. for the treatment of branching ratios of dissociative recombinations, $\mathrm{C}_{3} \mathrm{H}$ radical isomers can be among the major products of the dissociative recombination of the $\mathrm{C}_{3} \mathrm{H}_{5}^{+}$ion ${ }^{31}$. By reaction with a methyl radical $\mathrm{CH}_{3}, \mathrm{C}_{3} \mathrm{H}$ leads to $\mathrm{C}_{4} \mathrm{H}_{3}$, necessary for the formation of $\mathrm{C}_{6} \mathrm{H}_{5}$ (see R10):

$$
\mathrm{C}_{3} \mathrm{H}+\mathrm{CH}_{3} \longrightarrow \mathrm{C}_{4} \mathrm{H}_{3}+\mathrm{H}
$$

Since $\mathrm{CH}_{3}$ is very abundant, then the pathway leading to $\mathrm{C}_{4} \mathrm{H}_{3}$ is efficient. So the reaction $\mathrm{C}_{4} \mathrm{H}_{3}+\mathrm{C}_{2} \mathrm{H}_{3}$ is an important pathway for benzene formation under these conditions. The main production pathways for benzene in this high-energy environment are summarized in the diagram in Figure 3.

\section{The Formation of Toluene in the Photochemical Reactor}

The other significant result of this study, is the presence of a peak at m/z 92 which corresponds to toluene $\left(\mathrm{C}_{6} \mathrm{H}_{5} \mathrm{CH}_{3}\right)$ and another peak at m/z 91 which corresponds to the main fragment of $\mathrm{C}_{6} \mathrm{H}_{5} \mathrm{CH}_{3}$ due to electron impact ionization of the mass spectrometer. Its formation pathway remains an open question, but a likely mechanism can be inferred from our knowledge of the chemical system. Based on the reactivity of $\mathrm{C}_{6} \mathrm{H}_{5}$, its reaction with the most abundant radicals can be expected. Thus, in addition to the H-addition channel, $\mathrm{C}_{6} \mathrm{H}_{5}$ 


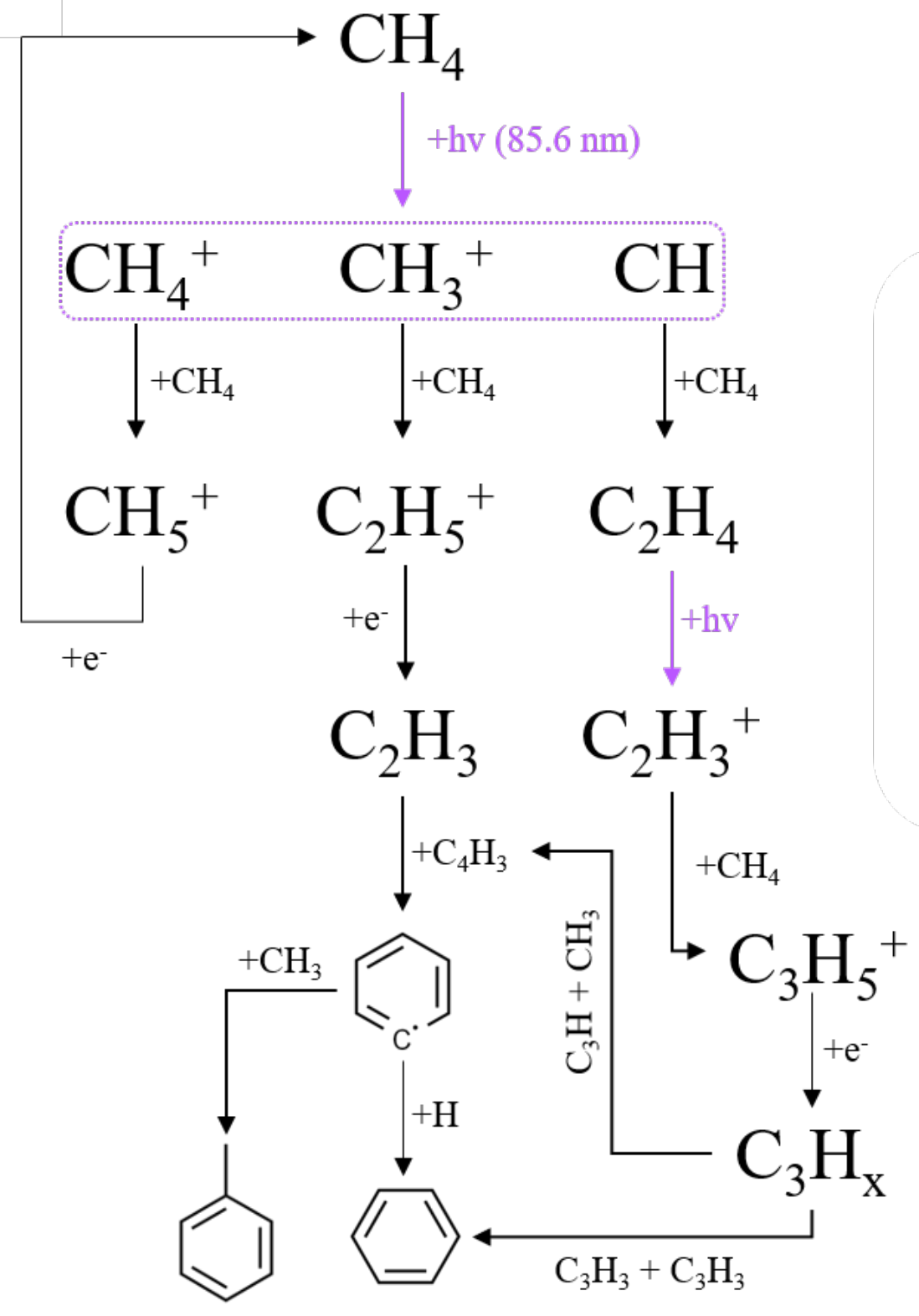

Figure 3: Main pathways derived from the experiments for benzene and toluene formation based on chemical reasoning taking into account the gas mixture composed of nitrogen and methane $(90 / 10 \%)$ irradiated, the wavelength of $85.6 \mathrm{~nm}$, and the overall pressure of 0.1 mbar.

could react with $\mathrm{CH}_{3}$ to form $\mathrm{C}_{6} \mathrm{H}_{5} \mathrm{CH}_{3}$, in agreement with the experimental study of the $\mathrm{C}_{3} \mathrm{H}_{3}+\mathrm{CH}_{3}$ recombination reaction. ${ }^{32}$ :

$$
\mathrm{C}_{6} \mathrm{H}_{5}+\mathrm{CH}_{3} \longrightarrow \mathrm{C}_{6} \mathrm{H}_{5} \mathrm{CH}_{3}
$$




\section{The Formation of Benzene-substituted Aromatics}

Peaks with a signal above the background noise are also observed at m/z 105 and 119, demonstrating that heavier compounds are formed in the reactor. Based on a mechanism $-\mathrm{H} /+\mathrm{CH}_{3}$ similar to the formation of toluene, a similar growth process on toluene itself can be inferred. H-abstraction would occur either on the lateral chain or on the aromatic core leading to two different growth evolutions (see Figure 4).

Based on a mechanism similar to the one proposed for formation of toluene, growth by H-abstraction on an aromatic followed by methyl-addition would lead successively to the formation of benzyl radical $\left(\mathrm{C}_{6} \mathrm{H}_{5} \mathrm{CH}_{2}\right)$ and ethylbenzene $\left(\mathrm{C}_{6} \mathrm{H}_{5} \mathrm{C}_{2} \mathrm{H}_{5}\right)$ at $\mathrm{m} / \mathrm{z} 106$ :

$$
\mathrm{C}_{6} \mathrm{H}_{5} \mathrm{CH}_{2}+\mathrm{CH}_{3} \longrightarrow \mathrm{C}_{6} \mathrm{H}_{5} \mathrm{C}_{2} \mathrm{H}_{5}
$$

Assuming that a similar $-\mathrm{H} /+\mathrm{CH}_{3}$ process allows a continued growth of aromatics, the formation of alkylbenzene with masses separated by an interval of 14 should be observed such as propylbenzene $\left(\mathrm{C}_{6} \mathrm{H}_{5} \mathrm{C}_{3} \mathrm{H}_{7}\right)$ at m/z 120 and butylbenzene $\left(\mathrm{C}_{6} \mathrm{H}_{5} \mathrm{C}_{4} \mathrm{H}_{9}\right)$ at m/z 134 . However, the fragmentation of these compounds due to the electron ionization of the experimental device, leads essentially to the formation of a fragment at $\mathrm{m} / \mathrm{z} 91^{33}$. It is then not possible to isolate their formation in the reactor. Thus the signals observed at m/z 105 and 119 correspond to other species.

The elimination of a $\mathrm{H}$-atom on an aromatic molecule in the reactor can be done either by photodissociation or by reaction with abundant radicals. If we consider the family of alkylbenzene $\left(\mathrm{C}_{6} \mathrm{H}_{5} \mathrm{CH}_{2} \mathrm{R}\right)$ of which toluene is the simplest molecule, abstraction can be done from the side chain or from a $\mathrm{C}-\mathrm{H}$ ring site. In the case of alkylbenzene reactions with radicals, the addition of a second radical to the carbon attached to the radical group causing its detachment can also be added as an exit channel ${ }^{34,35}$. Subsequent reactions by addition of methyl may therefore not take place solely by the formation of a side chain. Thus, alkylbenzene isomers with methyl and ethyl functions in different ring sites can potentially 
be formed in the reactor (see Figure 4). These species have a fragmentation spectrum by electron ionization whose main fragments are found at m/z 105 and $119^{33}$, whose observation of a signal at these masses in this work corroborates the hypothesis of the formation of aromatics with several functional groups in the reactor without disregarding the formation of aromatics with a single functional chain.

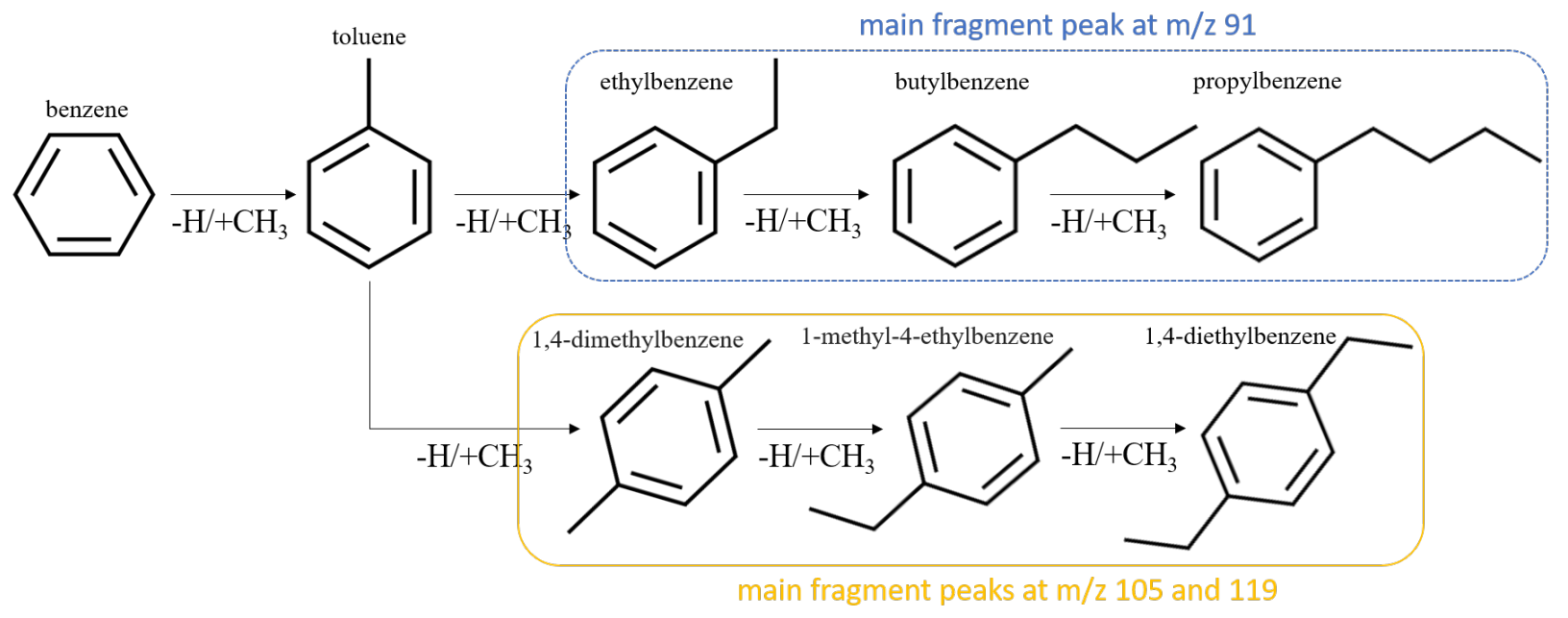

Figure 4: Mechanism through H-abstraction and subsequent methyl-addition for the formation of benzene-substituted aromatics in the reactor. The choice of the representation of the para isomers in this scheme is arbitrary. The formation of the meta isomers is as likely as the para isomers. This choice has been made to illustrate the two different possible molecular growth pathways from toluene in the reactor: from the lateral chain and from the aromatic core. The formation of isomers with alkyl groups in ortho position is usually not favoured because of steric effects ${ }^{36}$.

\section{DISCUSSION}

\section{Ion-driven Radical Chemistry toward Benzene}

As already shown in previous studies, the present investigation support that the production of benzene in the upper atmospheric layers of Titan is thought to be a combination of neutral reactions and dissociative recombination of heavy aromatic ions ${ }^{16,26,37}$. The formation of heavy ions is described as mainly initiated by the reaction chain starting from $\mathrm{C}_{2} \mathrm{H}_{5}^{+}$which 
form $\mathrm{C}_{4} \mathrm{H}_{5}^{+}$by reaction with acetylene ${ }^{38} \cdot \mathrm{C}_{4} \mathrm{H}_{5}^{+}$thereafter reacts with small hydrocarbons to form heavy ions like $\mathrm{C}_{6} \mathrm{H}_{6}^{+}$and $\mathrm{C}_{6} \mathrm{H}_{7}^{+39}$ :

$$
\begin{gathered}
\mathrm{C}_{2} \mathrm{H}_{5}^{+}+\mathrm{C}_{2} \mathrm{H}_{2} \longrightarrow \mathrm{C}_{4} \mathrm{H}_{5}^{+}+\mathrm{H}_{2} \\
\mathrm{C}_{4} \mathrm{H}_{5}^{+}+\mathrm{C}_{2} \mathrm{H}_{2} / \mathrm{C}_{2} \mathrm{H}_{4} \longrightarrow \mathrm{C}_{6} \mathrm{H}_{6}^{+} / \mathrm{C}_{6} \mathrm{H}_{7}^{+}+\mathrm{H} / \mathrm{H}_{2}
\end{gathered}
$$

The work presented in this paper highlights an indirect contribution of ions to the benzene formation chemistry, not by the recombination of heavy ions, but by the recombination of light ions $\left(\mathrm{CH}_{3}^{+}\right.$and $\left.\mathrm{C}_{2} \mathrm{H}_{5}^{+}\right)$which contribute as important additional sources of $\mathrm{CH}_{3}$ and $\mathrm{C}_{2} \mathrm{H}_{3}$ radicals which are further growth species ${ }^{40-42}$. This result is in agreement with the study of Plessis et al. ${ }^{43}$ whose main finding is that ions are an important source of radicals.

Radical association pathways are usually assumed to be more effective at low altitudes because they are pressure-dependent reactions. However, at $800 \mathrm{~km}$ where the abundance of benzene is maximum, we find ourselves in a transition domain where termolecular reactions are not negligible ${ }^{44}$. Nevertheless, the good agreement between the relative abundances of the species measured in this relatively low pressure experiment and in situ INMS measurements (see Figure 2), shows that radical reactions promoted by $\mathrm{CH}_{3}^{+}$appear to be efficient sources of benzene to explain its abundance in the upper layer of Titan's atmosphere. This is in agreement with previous articles in the literature showing that $\mathrm{CH}_{3}^{+}$promotes the formation of large organic molecules ${ }^{45,46}$.

\section{Experimental Confirmation of Toluene Production in Titan-like Conditions}

This work supports the formation of toluene in gas phase and is in line with the most recent

photochemical models predicting a significant abundance of toluene (see figure 5$)^{15,16}$. The mole fraction of toluene derived in this experiment coincides reasonably with the predictions of numerical simulations. The slight overestimation of the relative abundance of toluene 

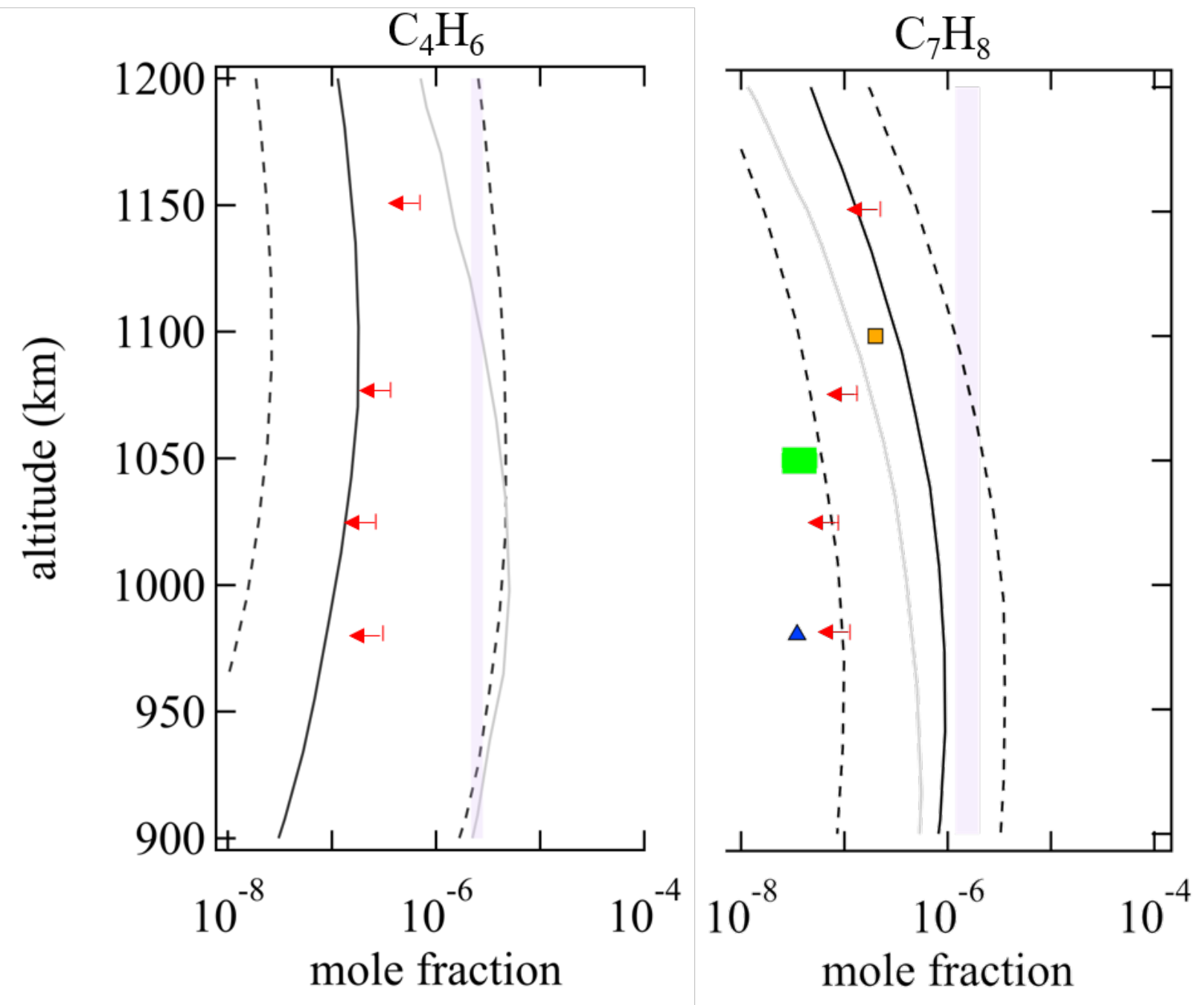

Figure 5: Comparison of mole fractions derived from this work (purple area) for $\mathrm{C}_{4} \mathrm{H}_{6}$ and $\mathrm{C}_{7} \mathrm{H}_{8}$ with in situ abundances derived from data analysis of the INMS measurements in Titan's thermosphere from 900 to $1,200 \mathrm{~km}$. Values include data analysis from Waite et al. ${ }^{3}$ (blue triangles), Vuitton et al. ${ }^{47}$ (orange squares), Cui et al. ${ }^{14}$ (red arrows), and Magee et al. ${ }^{48}$ (green area). The vertical mole fraction profiles derived from the most recent photochemical models of Titan's atmosphere are also represented (black lines from Dobrijevic et al. ${ }^{24}$ and Loison et al. ${ }^{16}$ and grey lines from Vuitton et al. ${ }^{15}$ ). 
in the experiment can be explained by the initial methane content in the gas mixture that was used as well as the potential fragmentation of alkylbenzene-derivatives of which certain main fragments correspond to toluene (cf. paragraph on the potential formation of benzenesubstituted aromatics).

The detection of toluene in Titan's atmosphere is currently a subject of debate. INMS detected a signal at masses 91 and 92 with a peak-to-peak ratio that supports the attribution of these two peaks to toluene. Despite the fact that some INMS spectra clearly show a signal to the masses coming from toluene, Vuitton et al. ${ }^{13}$ states that these intensities can be explained by catalytic effects on the walls within the INMS instrument. Indeed, the measurements carried out by INMS to detect benzene were made using an enhancement chamber placed in front of the mass spectrometer in order to "accumulate" the molecules and thus obtain a greater sensitivity for their detection ${ }^{7}$. However, since the setup used in the present work minimises the effects of the walls under operating conditions (see discussion in Bourgalais et al. ${ }^{18}$ ), the agreement between the derived mole fraction for toluene with the abundances measured by the INMS instrument and the most recent photochemical models questions the hypothesis that toluene could be an INMS artifact and would better confirm the detection of toluene by INMS in Titan's upper atmosphere.

This work also highlights the importance of toluene formation through barrierless reaction between methyl and phenyl radicals. However, the pathways of toluene formation and destruction remain too simple and approximate in photochemical models. Efforts must be undertaken to develop kinetic models of phenyl and toluene at low temperature, which constitute, as demonstrated in this work and in line with the literature ${ }^{49,50}$, dominant precursors in the initial photochemical steps leading to PAH formation and ultimately haze production. 


\section{Extensive Aromatic Growth through Sequential H-abstraction/ $\mathrm{CH}_{3}-$ addition Reactions}

Several growth mechanisms for PAHs in interstellar environments and combustion are proposed in the literature to date. The first mechanism is based on the formation of a radical by $\mathrm{H}$-abstraction followed by sequential addition of acetylene $\left(\mathrm{C}_{2} \mathrm{H}_{2}\right)$ but requires high temperatures $(>1,000 \mathrm{~K})^{51-53}$. Another mechanism initiated by the abstraction of a $\mathrm{H}$-atom followed by the addition of vinylacetylene (HAVA) allows to operate via barrierless reactions at temperatures representative of interstellar environments $(<200 \mathrm{~K})^{54-57}$. Alternative radical addition mechanisms with phenyl (PAC) ${ }^{50,58}$ and methyl $\mathrm{CH}_{3}$ (MAC) ${ }^{36,59,60}$, following a loss of $\mathrm{H}$ or $\mathrm{H}_{2}$ from an aromatic compound, are also effective processes for the growth of PAHs at low temperatures. Without disregarding the possibility of other low-temperature growth processes such as PAC and HAVA, this work puts forward for the first time the MAC mechanism as a potential lead to explain an efficient growth of aromatic molecules in Titan's atmosphere.

$\mathrm{CH}_{3}$ is the most abundant radical in Titan's atmosphere ${ }^{15}$ and as demonstrated here $\mathrm{CH}_{3}$ is a major player in the formation of the first aromatic molecules namely benzene and toluene, in line with literature ${ }^{16}$. Toluene is the most complex compound simulated by most of the photochemical models of Titan's atmosphere and in which the kinetic data of the phenyl radical reactions diverge strongly ${ }^{15,16,61}$. The model of Loison et al. ${ }^{16}$ is the only one to consider the formation of ethylbenzene $(\mathrm{m} / \mathrm{z}$ 106) via a mechanism initiated by the loss of a H-atom by photodissociation of toluene (see blue box in Figure 6$)^{62}$. Their model predicts that ethylbenzene is relatively abundant but also that the growth of aromatics stops at this stage. They mention that the growth pattern based on the reactivity of radicals resulting from the loss of $\mathrm{H}$-atom by an aromatic, cannot involve radicals of greater mass than benzyl because the photodissociation of ethylbenzene leads mainly to the loss of a methyl group as summarized in Figure 6 (cf. blue box).

However, based on the fragmentation pattern of alkylbenzenes and through the regular 
interval of $14 \mathrm{amu}$ from the detected peaks to the highest masses in the mass spectrum of Figure 2, this work highlights a potential efficiency of a $-\mathrm{H} /+\mathrm{CH}_{3}$ mechanism for aromatic growth in Titan's atmosphere. Loison et al. ${ }^{16}$ considers a chemical scheme involving a single isomer for $\mathrm{C}_{8} \mathrm{H}_{10}$, ethylbenzene but the abstraction of a $\mathrm{H}$-atom from toluene ring by a radical may be an alternative to the photodissociation of toluene which forms another $\mathrm{C}_{8} \mathrm{H}_{10}$ isomer (see yellow box in Figure 6). Indeed, the reaction of toluene with a H-atom is not implemented in photochemical models, but leads mainly to the formation of benzene and methylphenyl radicals $\left(\mathrm{C}_{6} \mathrm{H}_{4} \mathrm{CH}_{3}\right)$. The latters by reaction with a methyl radical can lead to the formation of dimethylbenzene isomers ${ }^{63}$. These isomers may subsequently be photodissociated by photons or react with $\mathrm{H}$ or $\mathrm{CH}_{3}$ to form methylbenzyl isomers ${ }^{64,65}$. However according to the kinetic data, it is likely that the formation of ethylbenzene is favoured over dimethylbenzene isomers in Titan's atmosphere because the exit channels of the reaction of toluene with $\mathrm{H}$ present barriers of a few $\mathrm{kcal} \mathrm{mol}^{-163}$. Under the experimental conditions of this work carried out at room temperature and in a limited photon environment, the conditions are probably more favorable for the formation of dimethylbenzene isomers. The addition of these reaction pathways is however necessary to study their impact on molecular growth in Titan's atmosphere.

Alternative reaction pathways, involving phenyl with abundant molecules such as $\mathrm{C}_{3} \mathrm{H}_{4}$ isomers, have been suggested in the literature to explain the growth of molecular complexity. These reactions lead directly to the formation of polyaromatic molecules such as indene, biphenyl or naphthalene ${ }^{66}$. However, no characteristic peak of these species can attest to their formation in the reactor. Moreover, the modeling of Loison et al. ${ }^{16}$ shows that the rapid rate coefficients of phenyl and benzyl radicals with $\mathrm{H}$ and $\mathrm{CH}_{3}$ make these polyaromatic formation pathways negligible. A growth pattern by addition of functional groups on a single aromatic ring seems to be the preferred pathway for the complexification of matter in Titan's atmosphere. 


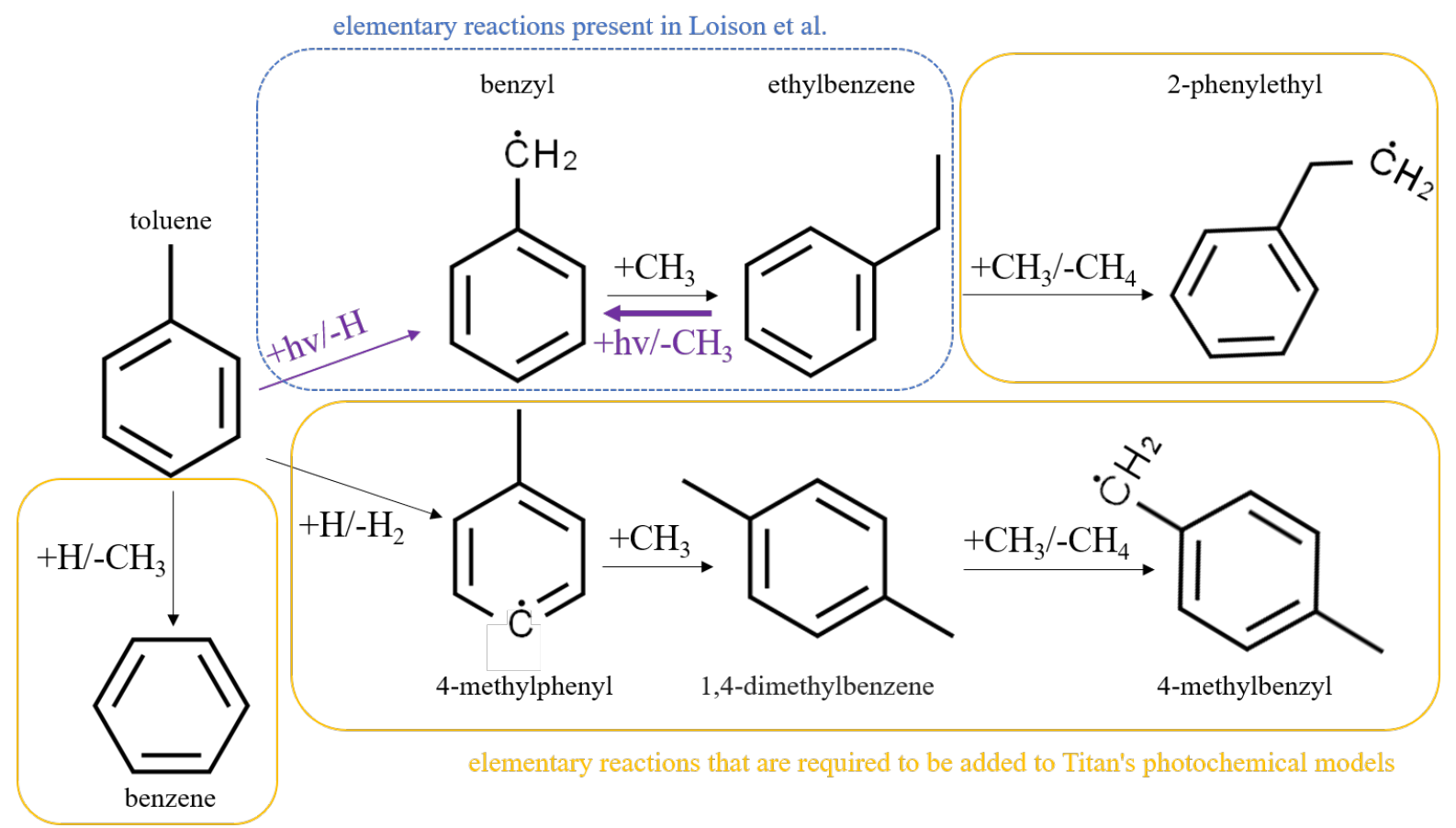

Figure 6: Potential reaction pathways to explain the radical growth in Titan's atmosphere from toluene according to a $\mathrm{H}$-elimination $/ \mathrm{CH}_{3}$-addition mechanism. It should be noted that the location of $\mathrm{H}$-loss on the reactions of ethylbenzene and 1,4dimethylbenzene has been arbitrarily chosen to illustrate the radical-addition/Helimination mechanism. The loss of an H-atom from the benzyl carbon rather might be more favorable since it would make a resonance-stabilized radical rather than a terminal radical.

\section{Perspectives}

This work shows that radical reactions can constitute one of the lines of research for a better understanding of the formation of aromatics in Titan's atmosphere. The fundamental parameters of these reactions remain indeed poorly known at the low temperatures of Titan's thermosphere (ca. 110-200 K) even if association reactions with large adducts can be rapid even at low pressure ${ }^{67}$. Further studies would beneficially be carried out on small radical reactions like $\mathrm{C}_{3} \mathrm{H}_{3}+\mathrm{C}_{3} \mathrm{H}_{3}, \mathrm{C}_{2} \mathrm{H}_{3}+\mathrm{C}_{4} \mathrm{H}_{3}$, and $\mathrm{C}_{3} \mathrm{H}_{3}+\mathrm{C}_{3} \mathrm{H}_{5}$ to evaluate precisely their branching ratios and the identity of the products under the temperature and pressure conditions representative of Titan's atmosphere. Indeed, radical reactions have significant rate constants but their contribution can be dampened depending 
on their concentration, justifying an accurate kinetic modeling. It should be noted that even if only benzene and toluene are considered at $\mathrm{m} / \mathrm{z} 78$ and 92 in this paper, isomeric branching ratios in kinetic models should be implemented whenever possible due to their potential difference in reactivity. For instance, as for $\mathrm{C}_{3} \mathrm{H}_{3}+\mathrm{C}_{3} \mathrm{H}_{3}, \mathrm{C}_{2} \mathrm{H}_{3}+\mathrm{C}_{4} \mathrm{H}_{3}$ may lead to benzene isomers while they do not seem to be produce by $\mathrm{C}_{6} \mathrm{H}_{5}+\mathbf{H}^{30,68}$.

Radical-molecule reactions are also promising avenues of investigation since they are usually barrierless making them potentially more important than radical reactions due to the fact that radicals can react with stable species that have longer lifetimes and higher concentrations. For instance, propargyl addition on $\mathrm{C}_{4} \mathrm{H}_{6}$ has been shown to be the dominant route to toluene formation in combustion environments with soot ${ }^{69,70}$. This reaction does not seem to present a significant barrier to entry and need to be updated in the PAH in Titan photochemical models. $\mathrm{C}_{4} \mathrm{H}_{6}$ has not yet been detected on Titan but seems to play an important role in the formation of benzene and toluene. As shown by Trevitt et al. ${ }^{71}$, the reaction between $\mathrm{CH}$ and propene $\left(\mathrm{C}_{3} \mathrm{H}_{6}\right.$ has been reported in CIRS spectra of Titan's stratosphere ${ }^{72}$ ) leads to the formation of several $\mathrm{C}_{4} \mathrm{H}_{6}$ isomers, mostly 1,3-butadiene. The mole fraction derived from the signal at $\mathrm{m} / \mathrm{z} 46$ in this work is consistent with the upper limit of Cui et al. ${ }^{14}$ and the predictions of Loison et al. ${ }^{16}$ (see Figure 5).

Other potential alternatives to the proposed mechanism based on $\mathrm{CH}_{3}$ for aromatic ring growth processes are also to be considered. As mentioned earlier, $\mathrm{C}_{2} \mathrm{H}_{4}$ photolysis and $\mathrm{C}_{2} \mathrm{H}_{5}^{+}$recombination are significant source of acetylene as depicted by $\mathrm{m} / \mathrm{z} 26$ in Figure 2. Acetylene is known to be abundant in Titan's atmosphere but its impact in this experiment is reduced due to its photolysis at $85.6 \mathrm{~nm}$ leading mainly to the formation of the $\mathrm{C}_{2} \mathrm{H}_{2}^{+}$ion which in turn reacts mostly with methane to give the $\mathrm{C}_{3} \mathrm{H}_{5}^{+}$ion. However, in Titan's atmosphere, acetylene gives mainly the ethynyl radical $\left(\mathrm{C}_{2} \mathrm{H}\right)$ which is highly reactive and 
leads to the growth of long carbon chains which can contribute indirectly to the formation of benzene and other aromatics (see Goulay et al. ${ }^{73}$ for instance). Small carbon radical like methylidyne $(\mathrm{CH})$ produced by methane photolysis might also play an important role in aromatic growth by reaction with alkene and alkyne molecules. Accurate chemical data on these subsystems, including branching ratio of the products provided by synchrotron based photoionization mass spectrometry ${ }^{74}$ and molecular cross-beam studies ${ }^{75}$, are required in detailed kinetic modeling.

Then the final question is how to grow the formation of PAHs beyond the formation of benzene and toluene? In line with the literature, this work shows that sequential reactions involving resonantly stabilized radicals such as propargyl $\left(\mathrm{C}_{3} \mathrm{H}_{3}\right)$, benzyl but also aromatic radicals such as phenyl are avenues to be explored in order to advance our knowledge of the growth of molecular complexity in Titan's atmosphere. Additionally, the dissociation pathway of ethylbenzene by elimination of a $\mathrm{H}$-atom is almost $10 \%$ taking into account the uncertainties $^{76}$. This branching ratio is not negligible because it leads to the formation of a highly reactive radical species and must therefore be accurately retranscribed in photochemical models. Reactions of ethylbenzene with abundant radicals such as $\mathrm{CH}_{3}$ can also be credible alternatives for the removal of a H-atom. These reactions have non-negligible rate coefficients and reasonable barriers below $10 \mathrm{kcal} \mathrm{mol}^{-1}$ that make them potentially contributing to the radical growth in Titan's atmosphere ${ }^{77}$ :

$$
\begin{gathered}
\mathrm{C}_{6} \mathrm{H}_{5} \mathrm{C}_{2} \mathrm{H}_{5}+\mathrm{H} \longrightarrow \mathrm{C}_{8} \mathrm{H}_{9}+\mathrm{H}_{2} \\
\mathrm{C}_{6} \mathrm{H}_{5} \mathrm{C}_{2} \mathrm{H}_{5}+\mathrm{CH}_{3} \longrightarrow \mathrm{C}_{8} \mathrm{H}_{9}+\mathrm{CH}_{4}
\end{gathered}
$$

As a conclusion the $\mathrm{CH}_{3}$-based mechanism enounced in this paper is one of the possible scenarios for aromatic growth in Titan's atmosphere. The experimental conditions with a wavelength at $85.6 \mathrm{~nm}$ allowed to explore a specific chemical regime with radical ion-guided pathways but other radical than $\mathbf{C H}_{3}$, may have 
a significant contribution to molecular complexity. These results intend to instill future updates of photochemical models of Titan's atmosphere.

From an experimental point of view, future orientations could be to increase the production rate of aromatics and PAHs in the reactor through the addition of a third species in the irradiated initial gas mixture. A compound such as acetylene could be a catalyst for chemical growth especially if it is used with an appropriate irradiation wavelength producing $\mathrm{C}_{2} \mathrm{H}$ radicals. In parallel, the use of a gas mixture with isotopic labeling on molecular nitrogen could also be relevant to probe the contribution of nitrogen chemistry in Titan's atmosphere by identifying the chemical pathways of nitrogen incorporation into organic molecules.

\section{Acknowledgement}

NC and JB thank the European Research Council for funding via the PrimChem project (grant agreement No. 636829). BM and JB thank the European Research Council for funding via the PHOTONIS project (grant agreement No. 695618). The laser source has been developed in the frame of the European Union's Horizon 2020 research and innovation program No. 682978 - EXCITERS. The authors acknowledge the support of the LOALIDYL-CELIA call for beamtime attribution. This work was partially funded by the IdEx Bordeaux Programm of the Agence Nationale de la Recherche through the LAPHIA (ANR10-IDEX-03-02).

\section{References}

(1) Hörst, S. M. Titan's atmosphere and climate. Journal of Geophysical Research: Planets 2017, 122, 432-482. 
(2) Coates, A.; Crary, F.; Lewis, G.; Young, D.; Waite, J.; Sittler, E. Discovery of heavy negative ions in Titan's ionosphere. Geophysical Research Letters 2007, 34.

(3) Waite, J.; Young, D.; Cravens, T.; Coates, A.; Crary, F.; Magee, B.; Westlake, J. The process of tholin formation in Titan's upper atmosphere. Science 2007, 316, 870-875.

(4) Dinelli, B.; López-Puertas, M.; Adriani, A.; Moriconi, M.; Funke, B.; García-Comas, M.; D'Aversa, E. An unidentified emission in Titan's upper atmosphere. Geophysical Research Letters 2013, 40, 1489-1493.

(5) Gautier, T.; Sebree, J. A.; Li, X.; Pinnick, V. T.; Grubisic, A.; Loeffler, M. J.; Getty, S. A.; Trainer, M. G.; Brinckerhoff, W. B. Influence of trace aromatics on the chemical growth mechanisms of Titan aerosol analogues. Planetary and Space Science 2017, 140, 27-34.

(6) Mahjoub, A.; Schwell, M.; Carrasco, N.; Benilan, Y.; Cernogora, G.; Szopa, C.; Gazeau, M.-C. Characterization of aromaticity in analogues of titan's atmospheric aerosols with two-step laser desorption ionization mass spectrometry. Planetary and Space Science 2016, 131, 1-13.

(7) Waite, J. H.; Niemann, H.; Yelle, R. V.; Kasprzak, W. T.; Cravens, T. E.; Luhmann, J. G.; McNutt, R. L.; Ip, W.-H.; Gell, D.; De La Haye, V., et al. Ion neutral mass spectrometer results from the first flyby of Titan. Science 2005, 308, 982-986.

(8) Coustenis, A.; Salama, A.; Schulz, B.; Ott, S.; Lellouch, E.; Encrenaz, T.; Gautier, D.; Feuchtgruber, H. Titan's atmosphere from ISO mid-infrared spectroscopy. Icarus 2003, $161,383-403$.

(9) Coustenis, A.; Achterberg, R. K.; Conrath, B. J.; Jennings, D. E.; Marten, A.; Gautier, D.; Nixon, C. A.; Flasar, F. M.; Teanby, N. A.; Bézard, B., et al. The composition of Titan's stratosphere from Cassini/CIRS mid-infrared spectra. Icarus 2007, 189, 3562. 
(10) Wilson, E.; Atreya, S.; Coustenis, A. Mechanisms for the formation of benzene in the atmosphere of Titan. Journal of Geophysical Research: Planets 2003, 108.

(11) Lavvas, P.; Coustenis, A.; Vardavas, I. Coupling photochemistry with haze formation in Titan's atmosphere, part I: Model description. Planetary and Space Science 2008, $56,27-66$.

(12) Lavvas, P.; Coustenis, A.; Vardavas, I. Coupling photochemistry with haze formation in Titan's atmosphere, Part II: Results and validation with Cassini/Huygens data. Planetary and Space Science 2008, 56, 67-99.

(13) Vuitton, V.; Yelle, R.; Cui, J. Formation and distribution of benzene on Titan. Journal of Geophysical Research: Planets 2008, 113.

(14) Cui, J.; Yelle, R.; Vuitton, V.; Waite Jr, J.; Kasprzak, W.; Gell, D.; Niemann, H.; Müller-Wodarg, I.; Borggren, N.; Fletcher, G., et al. Analysis of Titan's neutral upper atmosphere from Cassini Ion Neutral Mass Spectrometer measurements. Icarus 2009, 200, 581-615.

(15) Vuitton, V.; Yelle, R.; Klippenstein, S.; Hörst, S.; Lavvas, P. Simulating the density of organic species in the atmosphere of Titan with a coupled ion-neutral photochemical model. Icarus 2019, 324, 120-197.

(16) Loison, J.; Dobrijevic, M.; Hickson, K. The photochemical production of aromatics in the atmosphere of Titan. Icarus 2019, 329, 55-71.

(17) Woods, T. N.; Rottman, G. J. Solar ultraviolet variability over time periods of aeronomic interest. Geophysical Monograph-American Geophysical Union 2002, 130, 221234.

(18) Bourgalais, J.; Carrasco, N.; Vettier, L.; Gautier, T.; Blanchet, V.; Petit, S.; Descamps, D.; Fedorov, N.; Delos, R.; Gaudin, J. on an EUV Atmospheric Simula- 
tion chamber to Study the photochemical processes of titan's Atmosphere. Scientific Reports 2020, 10, 1-14.

(19) Comby, A.; Bloch, E.; Beauvarlet, S.; Rajak, D.; Beaulieu, S.; Descamps, D.; Gonzalez, A.; Guichard, F.; Petit, S.; Zaouter, Y., et al. Bright, polarization-tunable high repetition rate extreme ultraviolet beamline for coincidence electron-ion imaging. Journal of Physics B: Atomic, Molecular and Optical Physics 2020, 53, 234003.

(20) Lavvas, P.; Galand, M.; Yelle, R.; Heays, A.; Lewis, B.; Lewis, G.; Coates, A. Energy deposition and primary chemical products in Titan's upper atmosphere. Icarus 2011, 213, 233-251.

(21) Comby, A.; Descamps, D.; Beauvarlet, S.; Gonzalez, A.; Guichard, F.; Petit, S.; Zaouter, Y.; Mairesse, Y. Cascaded harmonic generation from a fiber laser: a milliwatt XUV source. Optics express 2019, 27, 20383-20396.

(22) Stevens, M. H.; Evans, J. S.; Lumpe, J.; Westlake, J. H.; Ajello, J. M.; Bradley, E. T.; Esposito, L. W. Molecular nitrogen and methane density retrievals from Cassini UVIS dayglow observations of Titan's upper atmosphere. Icarus 2015, 247, 301-312.

(23) Peng, Z.; Carrasco, N.; Pernot, P. Modeling of synchrotron-based laboratory simulations of Titan's ionospheric photochemistry. GeoResJ 2014, 1, 33-53.

(24) Dobrijevic, M.; Loison, J.; Hickson, K.; Gronoff, G. 1D-coupled photochemical model of neutrals, cations and anions in the atmosphere of Titan. Icarus 2016, 268, 313-339.

(25) Florescu-Mitchell, A.; Mitchell, J. Dissociative recombination. Physics reports 2006, $430,277-374$.

(26) McLain, J. L.; Poterya, V.; Molek, C. D.; Babcock, L. M.; Adams, N. G. Flowing afterglow studies of the temperature dependencies for dissociative recombination of 
$\mathrm{O} 2+, \mathrm{CH} 5+, \mathrm{C} 2 \mathrm{H} 5+$, and $\mathrm{C} 6 \mathrm{H} 7+$ with electrons. The Journal of Physical Chemistry A 2004, 108, 6704-6708.

(27) Baulch, D.; Cobos, C.; Cox, R.; Esser, C.; Frank, P.; Just, T.; Kerr, J.; Pilling, M.; Troe, J.; Walker, R., et al. Evaluated kinetic data for combustion modelling. Journal of Physical and Chemical Reference Data 1992, 21, 411-734.

(28) Kislov, V.; Nguyen, T.; Mebel, A.; Lin, S.; Smith, S. Photodissociation of benzene under collision-free conditions: An ab initio/Rice-Ramsperger-Kassel-Marcus study. The Journal of chemical physics 2004, 120, 7008-7017.

(29) Heays, A.; Bosman, v., AD; Van Dishoeck, E. Photodissociation and photoionisation of atoms and molecules of astrophysical interest. Astronomy \& Astrophysics 2017, 602, A105.

(30) Miller, J. A.; Klippenstein, S. J. The recombination of propargyl radicals and other reactions on a C6H6 potential. The Journal of Physical Chemistry A 2003, 107, 77837799

(31) Plessis, S.; Carrasco, N.; Pernot, P. Knowledge-based probabilistic representations of branching ratios in chemical networks: The case of dissociative recombinations. The Journal of chemical physics 2010, 133, 134110.

(32) Wang, B.; Hou, H.; Yoder, L. M.; Muckerman, J. T.; Fockenberg, C. Experimental and theoretical investigations on the methyl- methyl recombination reaction. The Journal of Physical Chemistry A 2003, 10\%, 11414-11426.

(33) Mallard, W.; Westley, F.; Herron, J.; Hampson, R.; Frizzell, D. NIST Chemical Kinetics Database: Version 6.0. National Institute of Standards and Technology, Gaithersburg, MD 1994, 
(34) Scott, M.; Walker, R. W. Addition of toluene and ethylbenzene to mixtures of H2 and $\mathrm{O} 2$ at $773 \mathrm{~K}$ : Part I: Kinetic measurements for $\mathrm{H}$ and $\mathrm{HO} 2$ reactions with the additives and a data base for $\mathrm{H}$ abstraction by $\mathrm{HO} 2$ from alkanes, aromatics and related compounds. Combustion and flame 2002, 129, 365-377.

(35) Ellis, C.; Scott, M. S.; Walker, R. W. Addition of toluene and ethylbenzene to mixtures of $\mathrm{H} 2$ and $\mathrm{O} 2$ at $772 \mathrm{~K}$ : Part 2: formation of products and determination of kinetic data for $\mathrm{H}+$ additive and for other elementary reactions involved. Combustion and flame 2003, 132, 291-304.

(36) Shukla, B.; Miyoshi, A.; Koshi, M. Role of methyl radicals in the growth of PAHs. Journal of the American Society for Mass Spectrometry 2010, 21, 534-544.

(37) Hamberg, M.; Vigren, E.; Thomas, R.; Zhaunerchyk, V.; Zhang, M.; Trippel, S.; Kaminska, M.; Kashperka, I.; af Ugglas, M.; Källberg, A., et al. Experimental studies of the dissociative recombination processes for the C6D6+ and C6D7+ ions. EAS Publications Series 2011, 46, 241-249.

(38) Kim, J.; Anicich, V.; Huntress Jr, W. Product distributions and rate constants for the reactions of $\mathrm{CH} 3+, \mathrm{CH} 4+, \mathrm{C} 2 \mathrm{H} 2+, \mathrm{C} 2 \mathrm{H} 3+, \mathrm{C} 2 \mathrm{H} 4+, \mathrm{C} 2 \mathrm{H} 5+$, and $\mathrm{C} 2 \mathrm{H} 6+$ ions with CH4, C2H2, C2H4, and C2H6. The Journal of Physical Chemistry 1977, 81, $1798-1805$.

(39) Anicich, V. G.; Wilson, P. F.; McEwan, M. J. An ICR study of ion-molecules reactions relevant to titan's atmosphere: An investigation of binary hydrocarbon mixtures up to 1 Micron. Journal of the American Society for Mass Spectrometry 2006, 17, 544-561.

(40) Shukla, B.; Koshi, M. A novel route for PAH growth in HACA based mechanisms. Combustion and flame 2012, 159, 3589-3596.

(41) Schenk, M.; Hansen, N.; Vieker, H.; Beyer, A.; Gölzhäuser, A.; Kohse-Höinghaus, K. 
PAH formation and soot morphology in flames of C4 fuels. Proceedings of the Combustion Institute 2015, 35, 1761-1769.

(42) Hansen, N.; Schenk, M.; Moshammer, K.; Kohse-Höinghaus, K. Investigating repetitive reaction pathways for the formation of polycyclic aromatic hydrocarbons in combustion processes. Combustion and Flame 2017, 180, 250-261.

(43) Plessis, S.; Carrasco, N.; Dobrijevic, M.; Pernot, P. Production of neutral species in Titan's ionosphere through dissociative recombination of ions. Icarus 2012, 219, 254266.

(44) Kobayashi, K.; Geppert, W. D.; Carrasco, N.; Holm, N. G.; Mousis, O.; Palumbo, M. E.; Waite, J. H.; Watanabe, N.; Ziurys, L. M. Laboratory Studies of Methane and Its Relationship to Prebiotic Chemistry. Astrobiology 2017, 17, 786-812.

(45) Imanaka, H.; Smith, M. A. Role of photoionization in the formation of complex organic molecules in Titan's upper atmosphere. Geophysical research letters 2007, 34.

(46) Imanaka, H.; Smith, M. A. EUV photochemical production of unsaturated hydrocarbons: Implications to EUV photochemistry in Titan and Jovian planets. The Journal of Physical Chemistry A 2009, 113, 11187-11194.

(47) Vuitton, V.; Yelle, R.; McEwan, M. Ion chemistry and N-containing molecules in Titan's upper atmosphere. Icarus 2007, 191, 722-742.

(48) Magee, B. A.; Waite, J. H.; Mandt, K. E.; Westlake, J.; Bell, J.; Gell, D. A. INMSderived composition of Titan's upper atmosphere: analysis methods and model comparison. Planetary and Space Science 2009, 57, 1895-1916.

(49) Yoon, Y. H.; Hörst, S. M.; Hicks, R. K.; Li, R.; de Gouw, J. A.; Tolbert, M. A. The role of benzene photolysis in Titan haze formation. Icarus 2014, 233, 233-241. 
(50) Shukla, B.; Susa, A.; Miyoshi, A.; Koshi, M. Role of phenyl radicals in the growth of polycyclic aromatic hydrocarbons. The Journal of Physical Chemistry A 2008, 112, 2362-2369.

(51) Frenklach, M. Reaction mechanism of soot formation in flames. Physical chemistry chemical Physics 2002, 4, 2028-2037.

(52) Wang, H.; Frenklach, M. A detailed kinetic modeling study of aromatics formation in laminar premixed acetylene and ethylene flames. Combustion and flame 1997, 110, $173-221$.

(53) Frenklach, M.; Wang, H. Detailed modeling of soot particle nucleation and growth. Symposium (International) on Combustion. 1991; pp 1559-1566.

(54) Zhao, L.; Kaiser, R. I.; Xu, B.; Ablikim, U.; Ahmed, M.; Joshi, D.; Veber, G.; Fischer, F. R.; Mebel, A. M. Pyrene synthesis in circumstellar envelopes and its role in the formation of 2D nanostructures. Nature Astronomy 2018, 2, 413-419.

(55) Zhao, L.; Kaiser, R. I.; Xu, B.; Ablikim, U.; Ahmed, M.; Evseev, M. M.; Bashkirov, E. K.; Azyazov, V. N.; Mebel, A. M. Low-temperature formation of polycyclic aromatic hydrocarbons in Titan's atmosphere. Nature Astronomy 2018, 2, 973979.

(56) Kaiser, R. I.; Parker, D. S.; Mebel, A. M. Reaction dynamics in astrochemistry: Lowtemperature pathways to polycyclic aromatic hydrocarbons in the interstellar medium. Annual Review of Physical Chemistry 2015, 66, 43-67.

(57) Parker, D. S.; Zhang, F.; Kim, Y. S.; Kaiser, R. I.; Landera, A.; Kislov, V. V.; Mebel, A. M.; Tielens, A. Low temperature formation of naphthalene and its role in the synthesis of PAHs (polycyclic aromatic hydrocarbons) in the interstellar medium. Proceedings of the National Academy of Sciences 2012, 109, 53-58. 
(58) Shukla, B.; Koshi, M. A highly efficient growth mechanism of polycyclic aromatic hydrocarbons. Physical Chemistry Chemical Physics 2010, 12, 2427-2437.

(59) Marin, L. G.; Bejaoui, S.; Haggmark, M.; Svadlenak, N.; de Vries, M.; SciammaO'Brien, E.; Salama, F. Low-temperature Formation of Carbonaceous Dust Grains from PAHs. The Astrophysical Journal 2020, 889, 101.

(60) Santoro, G.; Martínez, L.; Lauwaet, K.; Accolla, M.; Tajuelo-Castilla, G.; Merino, P.; Sobrado, J. M.; Peláez, R. J.; Herrero, V. J.; Tanarro, I., et al. The Chemistry of Cosmic Dust Analogs from C, C2, and C2H2 in C-rich Circumstellar Envelopes. The Astrophysical Journal 2020, 895, 97.

(61) Krasnopolsky, V. A. Chemical composition of Titan's atmosphere and ionosphere: Observations and the photochemical model. Icarus 2014, 236, 83-91.

(62) Fröchtenicht, R. The photodissociation of toluene studied by forward photofragment translational spectroscopy. The Journal of chemical physics 1995, 102, 4850-4859.

(63) Tian, Z.; Pitz, W. J.; Fournet, R.; Glaude, P.-A.; Battin-Leclerc, F. A detailed kinetic modeling study of toluene oxidation in a premixed laminar flame. Proceedings of the Combustion Institute 2011, 33, 233-241.

(64) Fujiwara, M.; Tanimoto, Y. Mechanism of Formation of o-Methylbenzyl Radical by Photodissociation of o-Xylene in Solution. The Journal of Physical Chemistry 1994, $98,5695-5700$.

(65) Shen, H.-P. S.; Oehlschlaeger, M. A. The autoignition of C8H10 aromatics at moderate temperatures and elevated pressures. Combustion and Flame 2009, 156, 1053-1062.

(66) Mebel, A. M.; Landera, A.; Kaiser, R. I. Formation mechanisms of naphthalene and indene: From the interstellar medium to combustion flames. The Journal of Physical Chemistry A 2017, 121, 901-926. 
(67) Vuitton, V.; Yelle, R.; Lavvas, P.; Klippenstein, S. Rapid association reactions at low pressure: Impact on the formation of hydrocarbons on Titan. The Astrophysical Journal $2011,744,11$.

(68) Mebel, A.; Lin, M.-C.; Chakraborty, D.; Park, J.; Lin, S.; Lee, Y. Ab initio molecular orbital/Rice-Ramsperger-Kassel-Marcus theory study of multichannel rate constants for the unimolecular decomposition of benzene and the $\mathrm{H}+\mathrm{C} 6 \mathrm{H} 5$ reaction over the ground electronic state. The Journal of Chemical Physics 2001, 114, 8421-8435.

(69) Pejpichestakul, W.; Ranzi, E.; Pelucchi, M.; Frassoldati, A.; Cuoci, A.; Parente, A.; Faravelli, T. Examination of a soot model in premixed laminar flames at fuel-rich conditions. Proceedings of the Combustion Institute 2019, 37, 1013-1021.

(70) Pejpichestakul, W.; Rupali, T.; Pelucchi, M.; Limin, C.; Heinz, P.; Ranzi, E.; Faravelli, T., et al. Mechanism Comparison for PAH Formation in Pyrolysis and Laminar Premixed Flames. 9th European Combustion Meeting 2019. 2019; pp 1-6.

(71) Trevitt, A. J.; Prendergast, M. B.; Goulay, F.; Savee, J. D.; Osborn, D. L.; Taatjes, C. A.; Leone, S. R. Product branching fractions of the $\mathrm{CH}+$ propene reaction from synchrotron photoionization mass spectrometry. The Journal of Physical Chemistry A 2013, 117, 6450-6457.

(72) Nixon, C. A.; Jennings, D. E.; Bezard, B.; Vinatier, S.; Teanby, N. A.; Sung, K.; Ansty, T. M.; Irwin, P. G.; Gorius, N.; Cottini, V., et al. Detection of propene in Titan's stratosphere. The Astrophysical journal letters 2013, 776, L14.

(73) Goulay, F.; Osborn, D. L.; Taatjes, C. A.; Zou, P.; Meloni, G.; Leone, S. R. Direct detection of polyynes formation from the reaction of ethynyl radical $(\mathrm{C} 2 \mathrm{H})$ with propyne ( $\mathrm{CH} 3-\mathrm{C}$ [triple bond, length as m-dash] $\mathrm{CH}$ ) and allene ( $\mathrm{CH} 2$ [double bond, length as m-dash] C [double bond, length as m-dash] CH 2). Physical Chemistry Chemical Physics 2007, 9, 4291-4300. 
(74) Trevitt, A. J.; Goulay, F. Insights into gas-phase reaction mechanisms of small carbon radicals using isomer-resolved product detection. Physical Chemistry Chemical Physics 2016, 18, 5867-5882.

(75) He, C.; Zhao, L.; Doddipatla, S.; Thomas, A. M.; Nikolayev, A. A.; Galimova, G. R.; Azyazov, V. N.; Mebel, A. M.; Kaiser, R. I. Gas-Phase Synthesis of 3-Vinylcyclopropene via the Crossed Beam Reaction of the Methylidyne Radical (CH; X2П) with 1, 3Butadiene (CH2CHCHCH2; X1Ag). ChemPhysChem 2020, 21, 1295-1309.

(76) Park, J.; Bersohn, R.; Oref, I. Unimolecular decomposition of methylsubstituted benzenes into benzyl radicals and hydrogen atoms. The Journal of chemical physics $\mathbf{1 9 9 0 ,}$ 93, 5700-5708.

(77) Nowakowska, M.; Herbinet, O.; Dufour, A.; Glaude, P.-A. Detailed kinetic study of anisole pyrolysis and oxidation to understand tar formation during biomass combustion and gasification. Combustion and Flame 2014, 161, 1474-1488. 
Graphical TOC Entry

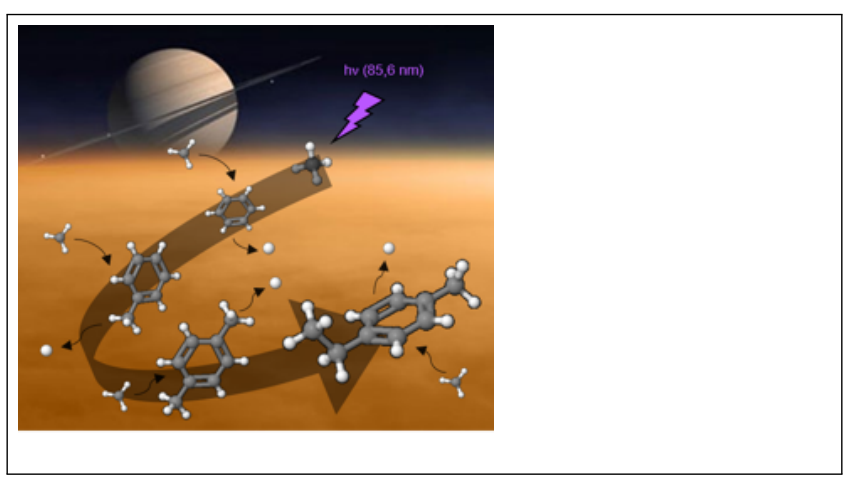

